\title{
The promised land of blended learning: Quizzes as a moderator
}

Citation for published version (APA):

Spanjers, I. A. E., Könings, K. D., Leppink, J., Verstegen, D. M. L., de Jong, N., Czabanowska, K., \& van Merriënboer, J. J. G. (2015). The promised land of blended learning: Quizzes as a moderator. Educational Research Review, 15, 59-74. https://doi.org/10.1016/j.edurev.2015.05.001

Document status and date:

Published: 01/06/2015

DOI:

10.1016/j.edurev.2015.05.001

Document Version:

Publisher's PDF, also known as Version of record

Document license:

Taverne

Please check the document version of this publication:

- A submitted manuscript is the version of the article upon submission and before peer-review. There can be important differences between the submitted version and the official published version of record.

People interested in the research are advised to contact the author for the final version of the publication, or visit the DOI to the publisher's website.

- The final author version and the galley proof are versions of the publication after peer review.

- The final published version features the final layout of the paper including the volume, issue and page numbers.

Link to publication

\footnotetext{
General rights rights.

- You may freely distribute the URL identifying the publication in the public portal. please follow below link for the End User Agreement:

www.umlib.nl/taverne-license

Take down policy

If you believe that this document breaches copyright please contact us at:

repository@maastrichtuniversity.nl

providing details and we will investigate your claim.
}

Copyright and moral rights for the publications made accessible in the public portal are retained by the authors and/or other copyright owners and it is a condition of accessing publications that users recognise and abide by the legal requirements associated with these

- Users may download and print one copy of any publication from the public portal for the purpose of private study or research.

- You may not further distribute the material or use it for any profit-making activity or commercial gain

If the publication is distributed under the terms of Article $25 \mathrm{fa}$ of the Dutch Copyright Act, indicated by the "Taverne" license above, 


\section{Review}

\section{The promised land of blended learning: Quizzes as a moderator}

\section{Ingrid A.E. Spanjers ${ }^{a, 1}$, Karen D. Könings ${ }^{\text {a,* }}$, Jimmie Leppink ${ }^{\text {a }}$, Daniëlle M.L. Verstegen a , Nynke de Jong a , Katarzyna Czabanowska b,c, Jeroen J.G. van Merriënboer ${ }^{\mathrm{a}}$}

a Department of Educational Development and Research, and School of Health Professions Education, Maastricht University, Maastricht, The Netherlands

${ }^{\mathrm{b}}$ Department of International Health \& CAPHRI, Maastricht University, Maastricht, The Netherlands

c Institute of Public Health, Faculty of Health Sciences, Jagiellonian University, Kraków, Poland

\section{A R T I C L E I N F O}

\section{Article history:}

Received 17 July 2014

Received in revised form 7 May 2015

Accepted 8 May 2015

Available online 14 May 2015

\section{Keywords:}

Blended learning

Hybrid learning

Effectiveness

Satisfaction

Meta-analysis

\begin{abstract}
A B S T R A C T
Blended learning, defined as a combination of face-to-face and online learning, is expected to lead to improved education. Besides, practical reasons, like increased access to education and resource management, are mentioned for its implementation. To examine whether the expectation of improved education is met, meta-analyses were conducted. They revealed that, on average, blended learning is somewhat more effective than more traditional learning. Additionally, students evaluated it as equally attractive, but seemed to perceive it as more demanding. In sum, blended learning is equal, or maybe even better, than more traditional learning. However, the effects on effectiveness, attractiveness and perceived demands differed much between studies. Moderator analyses found that quizzes positively affect the effectiveness and attractiveness of blended learning. Concluding, blended learning has potential to improve education, when thoughtfully designed, for example by the inclusion of frequent quizzes.
\end{abstract}

(c) 2015 Elsevier Ltd. All rights reserved.

\section{Contents}

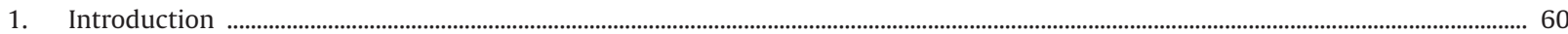

1.1. Improved education and practical reasons for the implementation of blended learning ....................................................... 60

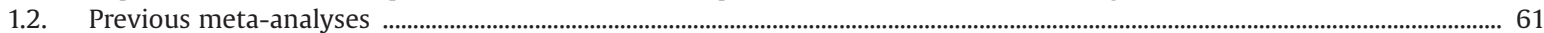

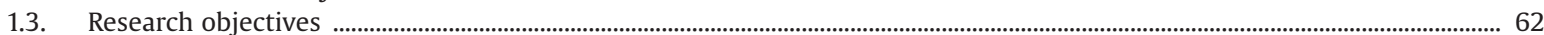

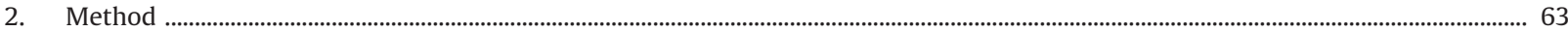

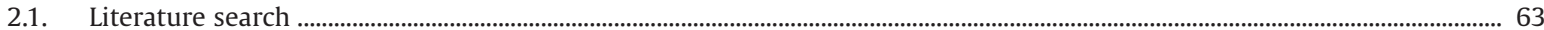

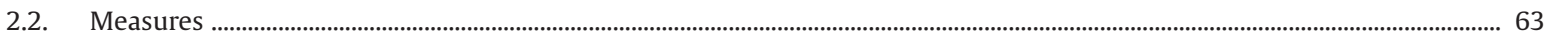

2.3. Coding of moderator variables ……….................................................................................................................................... 64

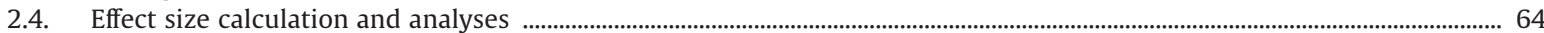

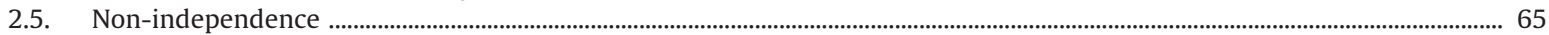

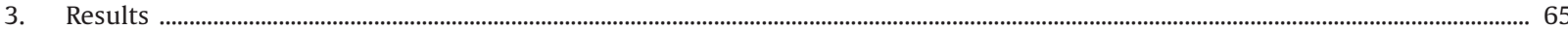

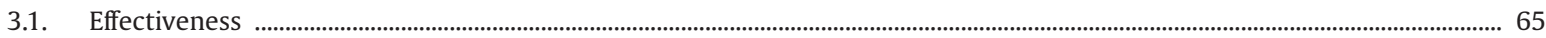

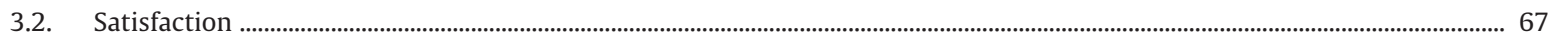

\footnotetext{
* Corresponding author. Tel.: +31 4338857 28; fax: +31 433885779 .

E-mail address: kd.konings@maastrichtuniversity.nl (K.D. Könings).

${ }^{1}$ Currently working at ResearchNed, Nijmegen, The Netherlands.
} 
3.3. Investment evaluations

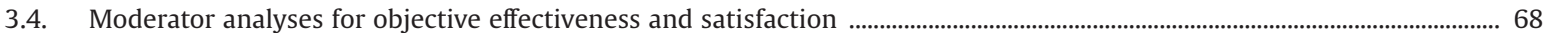

4.

Discussion

4.1. Comparison of our results with those of other meta-analyses ……...........................................................................................

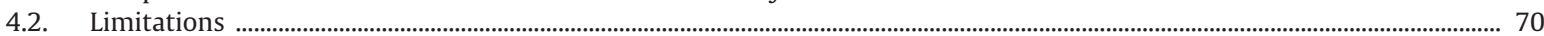

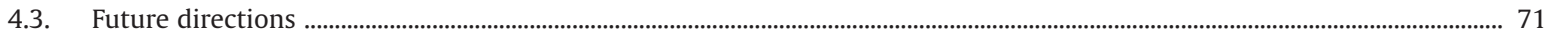

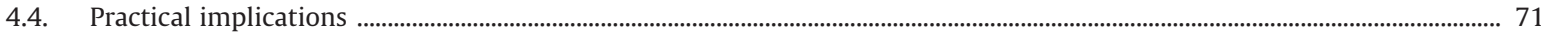

4.5. Theoretical background for the positive effects of quizzes on learning outcomes ................................................................. 71

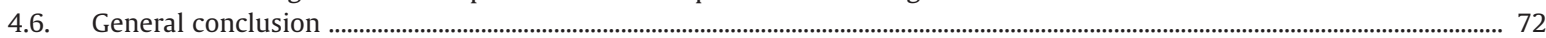

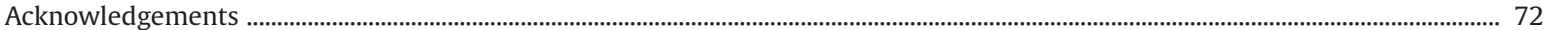

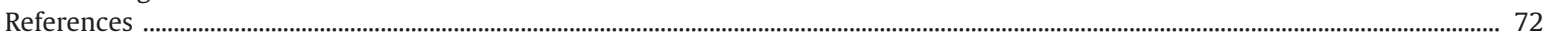

\section{Introduction}

Blended learning is a popular concept. A common aspect in many definitions of blended learning is that it combines online and face-to-face learning (e.g., Graham, 2013). Hence, it is assumed to combine the advantages of both (e.g., Delialioglu \& Yildirim, 2008; Feist, Ciccarelli, McFerron, \& Molleston, 2013; Vernadakis, Giannousi, Tsitskari, Antoniou, \& Kioumourtzoglou, 2012). Blended learning is widely used in higher education (Allen, Seaman, \& Garrett, 2007; Bonk, Kim, \& Zeng, 2006); and it is also used in K-12 education (e.g., Picciano, Seaman, Shea, \& Swan, 2012) and in the corporate world (e.g., Bonk et al., 2006; Kim, Bonk, \& Oh, 2008).

Blended learning is the focus of many research studies (Drysdale, Graham, Spring, \& Halverson, 2013). Part of the studies on blended learning are comparisons of blended and face-to-face learning (Drysdale et al., 2013; Halverson, Graham, Spring, Drysdale, \& Henrie, 2014). These studies are particularly interesting, as they enable us to draw conclusions about the effects of blended learning on effectiveness, student satisfaction and evaluations of required investments, compared to more traditional education. With a meta-analysis the results from these comparisons can be combined into one statistical synthesis, to draw stronger overall conclusions. This article presents meta-analyses examining the effects of blended learning on effectiveness, student satisfaction and evaluations of required investments. However, before describing our meta-analyses, first the main reasons for implementing blended learning are described in the next section. Subsequently findings of previous meta-analyses are discussed as well as the main methodological differences between those previous meta-analyses and our meta-analyses.

\subsection{Improved education and practical reasons for the implementation of blended learning}

Improving education is one of the main reasons to implement blended learning (e.g., Graham, 2006, 2009). Internet and computers, mostly used to access the internet in studies on blended learning, offer opportunities to include more, authentic, varied and different instructional materials and innovative learning activities. It is, for example, easier to incorporate frequent quizzes or self-tests in a blended learning environment than in a more traditional learning environment. Moreover, the computer can automatically score the answers of the students on those quizzes or self-tests and provide the students with feedback (e.g., Cole \& Robertson, 2006; Jia, Chen, Ding, \& Ruan, 2012; Riffell \& Sibley, 2005).

Additionally, the introduction of blended learning in a course might lead to rethinking of the instructional design and the investment of additional time and effort in the design (Kaleta, Skibba, \& Joosten, 2007). The capabilities and affordances of computers and internet as well as the additional time and effort put into the course design might trigger a shift toward a more active and learner-centered approach (Graham \& Robison, 2007; Kaleta et al., 2007; see also e.g., Adileh, 2012; Taradi, Taradi, Radić, \& Pokrajac, 2005; Vernadakis, Antoniou, Giannousi, Zetou, \& Kioumourtzoglou, 2011; Yang, 2012).

Furthermore, in blended learning learners have, to some extent, control over their learning. They can, for example, work on their own pace, choose to revisit materials and/or choose when to study (e.g., Feist et al., 2013; Salyers, 2007; Yapici \& Akbayin, 2012; Yang, 2012). This control might give them the possibility to adapt the learning materials to their individual needs or preferences (e.g., Cole \& Robertson, 2006; Kavadella, Tsiklakis, Vougiouklakis, \& Lionarakis, 2012). However, also other capabilities of blended learning might give students the possibility to adapt the learning materials to their individual needs or preferences. Examples of such capabilities are the choice between a variety of learning materials explaining concepts (Chandra \& Watters, 2012) or the choice to use e-mail and discussion fora (e.g., Cole \& Robertson, 2006). Blended learning is also assumed to better meet the needs of a diverse population of students (e.g., Adileh, 2012; Cole \& Robertson, 2006; Edwards, Kitzmiller, \& Breckenridge-Sproat, 2012; Picciano, 2009; Yapici \& Akbayin, 2012). It is, for example, stated to better meet the needs of students with different learning styles (Adileh, 2012; Rudestam \& Schoenholtz-Read, 2010; Yapici \& Akbayin, 2012). Blended learning has this capability, because it combines different forms of instruction (Picciano, 2009). Additionally, by the incorporation of technology, blended learning might also be better able to meet the needs of the current generation of students, who are surrounded by computers in their daily life (Costello, Lenholt, \& Stryker, 2004; Lancaster, Wong, \& Roberts, 2012). Additionally, blended learning can include activities which guide, support or force students to space their learning 
(e.g., Chandra \& Watters, 2012; Riffell \& Sibley, 2005). This spacing can positively affect the students' learning outcomes (Budé, Imbos, Van de Wiel, \& Berger, 2011; Dempster, 1988; Smith \& Rothkopf, 1984). An example of an activity which might support or force students in spacing their learning activities are frequent quizzes (Mawhinney, Bostow, Laws, Blumenfeld, \& Hopkins, 1971; Riffell \& Sibley, 2005). Frequent after school chat sessions in small groups moderated by the teacher might have a similar effect. They can also force or encourage students to space their learning activities (Chandra \& Watters, 2012).

Besides improving education, two other main reasons for the implementation of blended learning are specified by Graham (2006, 2009): Increased access to education and resource management. Blended learning might, for example, be more accessible for students who live far from the educational institute (e.g., Forte \& Root, 2011; Newhouse, Buckley, Grant, \& Idzik, 2013; Tamim, 2012). It might also be more accessible for students who have to combine the study with work or care for a family (e.g., Cole \& Robertson, 2006; Newhouse et al., 2013; Tamim, 2012). Additionally, when face-to-face contact time or seat time is reduced in blended learning, fewer classrooms might be needed. This might lead to a reduction in costs (e.g., Grasl et al., 2012; Perkins et al., 2012). However, these more practical reasons are according to some authors not reasonable or at least disputable (Jaggars \& Bailey, 2010; Means, Toyama, Murphy, \& Baki, 2013).

Blended learning is expected to improve education, because the advantages of online and face-to-face learning are combined (e.g., Delialioglu \& Yildirim, 2008; Taradi et al., 2005; Vernadakis et al., 2012). Possible advantages of the online part could be the opportunities to include more, authentic, varied and different instructional materials and innovative learning activities. In blended learning there is also still some face-to-face contact and interaction between students and between the students and teacher. Blended learning might, however, also combine the disadvantages of both (Graham, 2006, 2009). Students might, for example, have more difficulties in blended learning courses with managing their time, with selfregulating their learning (e.g., Aycock, Garnham, \& Kaleta, 2002; Kaleta et al., 2007; Senn, 2008) or with dealing with the complexity of authentic tasks (Van Merriënboer, Kirschner, \& Kester, 2003). Furthermore, giving students access to more learning materials and activities might have the consequence that they spend more time on the course. This might lead to improvements in learning outcomes, but it might make the course also more demanding (Kaleta et al., 2007). This could make learning less efficient rather than more efficient (Graham \& Robison, 2007).

Consequently, it is not sure that blended learning improves education. Hence, a study examining the effects of blended learning on effectiveness, student satisfaction and evaluations of required investments is needed. Our study investigates with meta-analyses whether blended learning is more, equally or less effective and attractive as more traditional learning. Besides, it will explore whether blended learning is evaluated to require more, equal or less investments than more traditional learning. Learning environments do not directly influence students' learning behavior and outcomes. Their effects are mediated by the students' perceptions (Könings, Brand-Gruwel, \& Van Merriënboer, 2005; Könings, Brand-Gruwel, Van Merriënboer, \& Broers, 2008). Hence, it is important to study the effects of a learning environment on students' satisfaction and evaluations of required investments, in addition to its effects on effectiveness.

\subsection{Previous meta-analyses}

Previous meta-analyses examining the effect of blended learning or blended and computer technology-enhanced learning on learning outcomes and student satisfaction are presented in five articles: Bernard, Borokhovski, Schmid, Tamim, and Abrami (2014); Means et al. (2013); Schmid et al. (2014); Sitzmann, Kraiger, Stewart, and Wisher (2006); and Tamim, Bernard, Borokhovski, Abrami, and Schmid (2011). As can be seen in Table 1, these previous meta-analyses mostly found positive effects in the small to medium range for learning outcomes. The only exception is the medium positive effect size for procedural knowledge found by Sitzmann et al. (2006). However, this effect size is based on a small sample (i.e., six studies). Only a few of these previous meta-analyses examined also students' evaluation, satisfaction, or reactions, and their results were less consistent (see Table 1). Schmid et al. (2014) mostly found positive effects in the small to medium range. The exception is one trivial positive effect size. In contrast to these results of Schmid et al. (2014), Sitzmann et al. (2006) found a trivial negative effect.

Our meta-analyses, however, aim to give a better overview of the effects on effectiveness and student satisfaction of current implementation of blended learning than previous meta-analyses. They differ from previous meta-analyses in four ways (see Table 1). First, previous meta-analyses also included older studies. The possibilities of the internet and web-based tools have increased a lot, since the nineties. Many more videos, animations and other types of multimedia are available online yet than in the nineties, for example. Additionally, the availability and the capabilities of the computers and infrastructure in schools have improved much since then. This might have affected the design of blended learning environments, and as a consequence, also the effects of blended learning on effectiveness and student satisfaction. Therefore, we have excluded publications from before 2005. Second, previous meta-analyses often did not include all levels of education and training, which might have limited their findings. Hence, in our meta-analyses all levels of education and training are included. Third, in previous meta-analyses the affective measures also included self-evaluations of learning progress (Schmid et al., 2014) and perceptions of difficulty (Sitzmann et al., 2006). By consequence, measures combined rather distinct concepts that might not clearly be related to each other. Our satisfaction measure focuses more on student satisfaction with the course and/or teacher rather than on a combination of evaluations. Fourth, previous meta-analyses have used different search terms and different definitions of blended learning. This has influenced the studies found and included, and, by consequence, might have affected the effects of blended learning on learning outcomes and satisfaction found. By following the considerations 
Table 1

Average effect sizes found in previous meta-analyses for learning outcomes and satisfaction.

\begin{tabular}{|c|c|c|c|}
\hline Study & $\begin{array}{l}\text { Average effect } \\
\text { size (effectiveness) }\end{array}$ & $\begin{array}{l}\text { Average effect } \\
\text { size (satisfaction) }\end{array}$ & Main differences with our meta-analyses \\
\hline Bernard et al. (2014) & +0.33 & & $\begin{array}{l}\text { - Different definition for blended learning } \\
\text { - Part from a combined dataset } \\
\text { - Included older studies as well } \\
\text { - Formal post-secondary education only }\end{array}$ \\
\hline $\begin{array}{l}\text { Means et al. (2013) } \\
\text { Analysis for blended } \\
\text { learning }\end{array}$ & +0.35 & & $\begin{array}{l}\text { - Search terms aimed at web-based learning } \\
\text { - Different definition for blended learning } \\
\text { - Included older studies as well }\end{array}$ \\
\hline $\begin{array}{l}\text { Tamim et al. (2011) } \\
\text { Secondary meta-analysis }\end{array}$ & +0.35 & & $\begin{array}{l}\text { - Blended and technology-enhanced learning combined } \\
\text { - Included older meta-analyses as well }\end{array}$ \\
\hline $\begin{array}{l}\text { Tamim et al. (2011) } \\
\text { Validation study }\end{array}$ & +0.33 & & $\begin{array}{l}\text { - Blended and technology-enhanced learning combined } \\
\text { - Included older meta-analyses as well }\end{array}$ \\
\hline Schmid et al. (2014) & Combined: +0.27 & +0.21 & - Blended and technology-enhanced learning combined \\
\hline Whole data-set & $\begin{array}{l}\text { No technology in } \\
\text { control: }+0.25 \\
\text { Some technology } \\
\text { in control: }+0.31\end{array}$ & $\begin{array}{l}\text { No technology in } \\
\text { control: }+0.27 \\
\text { Some technology } \\
\text { in control: }+0.11\end{array}$ & $\begin{array}{l}\text { - Included older studies as well } \\
\text { - Formal post-secondary education only } \\
\text { - Included self-evaluation as well }\end{array}$ \\
\hline $\begin{array}{l}\text { Schmid et al. (2014) } \\
\text { Re-analysis for blended } \\
\text { learning }\end{array}$ & $\begin{array}{l}\text { No technology in } \\
\text { control: }+0.35 \\
\text { Some technology in } \\
\text { control: }+0.28\end{array}$ & $\begin{array}{l}\text { No technology in } \\
\text { control: }+0.33 \\
\text { Some technology in } \\
\text { control: insufficient } \\
\text { studies }\end{array}$ & $\begin{array}{l}\text { - Different definition for blended learning } \\
\text { - Part from a combined dataset } \\
\text { - Included older studies as well } \\
\text { - Formal post-secondary education only } \\
\text { - Affective measures included self-evaluation }\end{array}$ \\
\hline $\begin{array}{l}\text { Sitzmann et al. (2006) } \\
\text { Analysis for blended } \\
\text { learning }\end{array}$ & $\begin{array}{l}\text { Declarative knowledge: }+0.34 \\
\text { Procedural knowledge: }+0.52\end{array}$ & -0.15 & $\begin{array}{l}\text { - Search terms aimed at web-based learning } \\
\text { - Included older studies as well } \\
\text { - Work-related trainings only } \\
\text { - Affective measures included perceptions of difficulty }\end{array}$ \\
\hline
\end{tabular}

of the authors of articles, we aim to provide a purer measure of the effects of blended learning on learning outcomes and satisfaction as it is defined by the authors of articles.

In our meta-analyses, the considerations of the authors of articles were followed with some restrictions. In order to be included, blended learning had to be a combination of online and face-to-face education in which the e-learning part was more than only an addition to the more traditional education in the control condition. So, authors of articles were not followed when blended learning was not a combination of online and face-to-face learning. When the online part was only an addition in time, resources or activities to the more traditional education, the comparison between education with this addition and without it would not be a sensible comparison. Therefore, studies were excluded when the e-learning part did not replace a part of the learning time, resources or activities from the more traditional learning environment.

Blended learning might require the investment of more time, effort or work, as suggested by Sitzmann et al. (2006) when explaining the slightly negative effect size for learners' reactions in their study (see Table 1). This investment of more time, effort or work could also have led to higher effectiveness of blended learning, and, hence, to the positive effect sizes for learning outcomes found by them (see Table 1). However, they state that more research is needed to examine this suggestion. Therefore this issue will be explored in our meta-analysis on evaluations of required investments.

\subsection{Research objectives}

The objective of this study is to investigate the effectiveness, student satisfaction and student evaluations of required investments of time, work or effort with blended learning compared with more traditional learning. In addition to the average effects, the variability of the effects of blended learning on these different outcome measures is examined. When significant variability is found, it is interesting to consider conditions under which blended learning is more or less successful. For this purpose the following variables were examined in moderator analyses for learning outcomes and satisfaction: Allocation (i.e., way of assigning students to either blended learning or control condition), educational level, subject matter, duration, communication and quizzes.

Allocation is studied because it might affect the results when students are in the condition which they prefer. Postsecondary education differs in a number of ways from primary and secondary education. To explore whether this affects the results, this categorization was included in the moderator analyses. Additionally, it was explored whether blended learning was more effective or attractive for particular types of subject matter. It might also be that students need to get used to the new type of education. Hence, it might be that effects on effectiveness and satisfaction can only be found in courses with a longer duration. On the other hand, it might be that the effects of a new type of education on effectiveness and satisfaction can only be found as long as the education is perceived as new and special by the students. This latter would imply that effects of blended learning on effectiveness and satisfaction would only be found with short courses or trainings. The effects of blended learning on effectiveness and satisfaction probably also depend on how blended learning is implemented. Hence, two features of the implementation are included as moderators. It is examined whether the type of 
Table 2

Search terms used in the literature search.

\begin{tabular}{lll}
\hline First group of terms & Second group of terms & Third group of terms \\
\hline $\begin{array}{c}\text { Blended, hybrid, } \\
\text { "mixed mode", or } \\
\text { web-enhanced }\end{array}$ & $\begin{array}{l}\text { Learn*, instruct*, educ*, teach*, curricul*, } \\
\text { course, lesson, format, module, class, classes, } \\
\text { program, or programme }\end{array}$ & $\begin{array}{l}\text { Off-line, offline, *ampus*, lectur*, workshop, hands-on, } \\
\text { control, traditional*, formal*, regular*, conventional*, } \\
\text { face-to-face, "face to face", f2f, in-class, classical*, or classroom }\end{array}$ \\
\hline
\end{tabular}

communication in the distance part of the blended learning environment affects the results for effectiveness and satisfaction. A distinction is made between no information on communication, asynchronous communication only, and both asynchronous and synchronous communication. Asynchronous communication provides learners with more flexibility with regard to the moment at which they study. It might also lead to more reflective learner behavior. But, on the other hand, asynchronous communication lacks the spontaneity and more social interactions of synchronous communication (Rudestam \& Schoenholtz-Read, 2010). Quizzes, tests or self-assessments are learning activities which can easily be implemented online, especially because the computer can score the answers of the students and provide students with feedback (e.g., Cole \& Robertson, 2006; Jia et al., 2012; Riffell \& Sibley, 2005). Quizzes have been found to lead to better learning outcomes (Bangert-Drowns, Kulik, \& Kulik, 1991; Dirkx, Kester, \& Kirschner, 2014; Pashler et al., 2007; Roediger \& Karpicke, 2006) and more favorable student opinions (Bangert-Drowns et al., 1991). Hence, the effects of including quizzes on the effectiveness and satisfaction of blended learning are examined.

\section{Method}

\subsection{Literature search}

Records with one or more terms from each of three groups of terms (see Table 2) in the title or abstract were searched in PubMed on August 12, 2013 and in ERIC and PsycInfo on August 14, 2013. Additionally, a limitation to peer reviewed sources was set in PsycInfo and ERIC and a limitation to the English language in PsycInfo and PubMed. Subsequently, records of sources published before 2005 were excluded. In total 2463 non-duplicate records of sources published in or after 2005 were found.

The abstracts of these records were rated as either irrelevant or potentially relevant by two of the authors (either IS or KK). Sources which were clearly not about a comparison between blended learning and more traditional learning were excluded. Based on 238 abstracts (about 10\%) rated by both, the interrater reliability was found to be good (kappa $=0.72$ ). From the 2463 abstracts, 222 sources were selected as potentially relevant. Three articles were not obtained and one source was excluded because it was a report rather than a peer-reviewed journal article. The full texts of 218 records were retrieved and inspected to determine whether the study described was suitable for inclusion. A couple of borderline cases were discussed. Finally, 47 articles were included. The reasons for exclusion and the number of studies excluded for that reason are presented in Table 3.

\subsection{Measures}

Objective measures and subjective measures of effectiveness were used. Objective effectiveness measures include the scores on a post-test, gains in test scores, course grades, and evaluations of assignments, exercises or skills by someone else than the student himself. Results were excluded when measures were clearly aimed at measuring the results at a delayed point in time. Subjective effectiveness measures include self-assessment and course evaluation measures, being post-test

Table 3

Reasons for exclusion of articles and numbers of articles deleted for that reason.

Reason
$\begin{aligned} & \text { Study did not quantitatively compare blended learning and more traditional face-to-face learning with two independent groups of } \\ & \text { students } \\ & \text { Difference in the content, aims, or tests for objective effectiveness or too large difference in pedagogy and/or learning activities in the } \\ & \text { two conditions }\end{aligned}$
No a priori competence measurement for objective effectiveness, or a clear difference in favor of the blended group on the a priori
competence measurement, and no data for satisfaction, subjective effectiveness or investment evaluations
Insufficient statistics presented in the article and no sufficient additions obtained by the author
Severe methodological or statistical flaws, for example multiple inclusion of data of students or less than eight students in one or
both conditions
Other, for example no useful measure, only dichotomous measures or only evaluation of online part of the blended learning

N.B. An article might be excluded for more than one reason, but in this table only one reason for exclusion is given for each article. 
scores or gain scores on a perceived self-efficacy measure, and self-assessment ratings with regard to the achievement of course objectives, subjective learning gains, amount learned, and ability or confidence in ability. The satisfaction measures that were used were course evaluation measures and subscales and items evaluating different aspects of the course, course materials and instructors. Items about difficulty and self-evaluation were excluded when data were provided on an item level rather than on an aggregated level. Investment evaluations are measured by items asking for the amount of work or effort devoted or the appropriateness of the time or work devoted.

\subsection{Coding of moderator variables}

As can be seen in Table 4, six variables were coded as possible moderators: Allocation (i.e. way of assigning students to either blended learning or control condition), level of education, subject matter, duration, type of communication in the online or distance part of the blended learning and quizzes. The communication in the online or distance part could be twoway or one-way and between the teacher and students and/or between students. The availability of quizzes included the availability of self-tests and frequently administered other tests as well.

In the moderator analyses only categories with five or more studies were included. For communication and for quizzes, the missing category was seen as a meaningful category, when five or more studies were available. For allocation and for duration it was not considered meaningful to include the missing category in the moderator analyses.

\subsection{Effect size calculation and analyses}

Data were analyzed with the software program Comprehensive Meta-Analysis (CMA, Version 2.2.064). Hedges' g was used, which is based on Cohen's d, but adjusted for small sample size bias (Hedges, 1981). Hedges' g was calculated by CMA based on means, standard deviations and numbers of participants, based on differences between means, numbers of participants and $t$-values or square roots of F-values, or based on Cohen's d and variance calculated by Wilson (n.d.) Practical meta-analysis effect size calculator (http://www.campbellcollaboration.org/escalc/html/EffectSizeCalculator-Home.php). This latter effect size calculator was used when studies presented means, standard errors and numbers of participants, frequency distributions or numbers of participants and distributions with proportions. For some effect sizes numbers of participants had to be estimated, based on, for example, the reported degrees of freedom. According to Cohen (1988) an effect size of 0.2 is small, 0.5 medium-sized and 0.8 large.

Random effects models, in which the study's variance consists of a within study variance component and a between studies variance component, were used. Studies were weighted by the inverses of their variances (Borenstein, Hedges, Higgins, \& Rothstein, 2009; Lipsey \& Wilson, 2001). The square root of the between studies variance component is an estimation of tau (i.e., the standard deviation of the true effects) (Borenstein et al., 2009).

When the $Q$-test for heterogeneity is significant, this implies that the variability in the effect sizes is larger than can be expected based on sampling error only. To give an indication of the magnitude of the heterogeneity (rather than its significance) $I^{2}$ is reported, which can be interpreted as the 'percentage of total variation across studies that is due to heterogeneity

Table 4

Moderator variables coded with the associated categories.

\begin{tabular}{|c|c|}
\hline Moderator variable & Categories \\
\hline Allocation & $\begin{array}{l}\text { - Selected (i.e. allocation based on own choice of students, based on on-campus and off-campus or on access to } \\
\text { computers for students in the blended group) } \\
\text { - Groups (i.e. allocation based on groups, like classes, years or semesters) } \\
\text { - Unknown type of allocation or none of the previous ones }\end{array}$ \\
\hline Educational level & $\begin{array}{l}\text { - K-12 } \\
\text { - Post-secondary }\end{array}$ \\
\hline Subject matter & $\begin{array}{l}\text { - Alpha (i.e. language or music) } \\
\text { - Beta (i.e. physics, science and technology, non-human-health-related biology, engineering, statistics, programming } \\
\text { and other computer-related subjects) } \\
\text { - Gamma (i.e. wellness, psychology, interpersonal skills, social work, educational technology or economic, financial, } \\
\text { marketing and management subjects) } \\
\text { - Health related (i.e. human-health-related biology or medical, paramedical, dentistry or nursing subjects) } \\
\text { - Unknown }\end{array}$ \\
\hline Duration & $\begin{array}{l}\text { - Long (i.e. } 14 \text { or more weeks or a semester, not explicitly stated to be shorter than } 14 \text { weeks) } \\
\text { - Short (i.e. between a few hours on one day until } 13 \text { weeks, including semesters shorter than } 14 \text { weeks) } \\
\text { - Unknown number of weeks }\end{array}$ \\
\hline $\begin{array}{l}\text { Communication in the } \\
\text { online or distance part }\end{array}$ & $\begin{array}{l}\text { - Both (i.e. synchronous as well as asynchronous communication) } \\
\text { - Asynchronous (i.e. asynchronous communication or communication of an unspecified or insufficiently specified type) } \\
\text { - No (i.e. no information on communication or no communication) }\end{array}$ \\
\hline Quizzes & $\begin{array}{l}\text { - Both (i.e. available in both conditions) } \\
\text { - Blended only (i.e., available in blended learning, but not available in or insufficient information for more traditional } \\
\text { learning) } \\
\text { - No (i.e. no information for or not available in both conditions) }\end{array}$ \\
\hline
\end{tabular}


rather than chance' (Higgins, Thompson, Deeks, \& Altman, 2003, p. 558). $I^{2}$ is considered to be small if about $25 \%$, moderate if about $50 \%$ and high if about $75 \%$ (Higgins et al., 2003).

Moderator analyses of the analog to variance analysis type were performed for objective effectiveness and satisfaction. For subjective effectiveness and investment evaluations too few studies were found to conduct moderator analyses. Mixed effects models with a pooled estimate of tau were used (Borenstein et al., 2009). To further explore the effects of significant moderator variables with more than two categories, post-hoc pairwise comparisons were conducted. To correct for the use of multiple post-hoc tests, the alpha level for those tests was divided by the number of post-hoc pairwise comparisons conducted.

For objective effectiveness, subjective effectiveness and satisfaction, histograms and boxplots of the effect size distribution made with SPSS and standardized residuals obtained from CMA were used to determine which study was the most deviant from the other studies. To determine whether outliers might have substantially affected the results for these three concepts, it was examined with 'one study removed' analyses what the results were when that most deviant study was excluded. Additionally, it was determined based on the statistics of kurtosis and skewness obtained with SPSS whether the effect size distributions did not substantially deviate from normality.

\subsection{Non-independence}

One study presented descriptive statistics for boys and girls in the two conditions separately. These data were combined with CMA. Three studies presented data for two control groups and one blended learning group or for one control group and two or three blended learning groups. Before being entered in CMA, the descriptive statistics of these studies were pooled for the condition for which there were two or three groups with the following formulas:

$$
M=\left(n_{1} * M_{1}+n_{2} * M_{2}+n_{3} * M_{3}\right) /\left(n_{1}+n_{2}+n_{3}\right)
$$

and

$$
s d=\operatorname{SQRT}\left(\left(\mathrm{df}_{1} * \mathrm{sd}_{1} * \mathrm{sd}_{1}+\mathrm{df}_{2} * \mathrm{sd}_{2} * \mathrm{sd}_{2}+\mathrm{df}_{3} * \mathrm{sd}_{3} * \mathrm{sd}_{3}\right) /\left(\mathrm{df}_{1}+\mathrm{df}_{2}+\mathrm{df}_{3}\right)\right)
$$

When statistics for measures assessing different concepts (i.e., objective effectiveness, subjective effectiveness, satisfaction, and investment evaluations) were obtained from the same study, the effect sizes were treated as independent data points. When sufficient statistics for measures assessing the same concept were obtained from the same study, these statistics were combined in CMA with a fixed effect meta-analysis, before being entered in the main meta-analyses. In combining these data a correlation of 1.0 was assumed between the measures. When different numbers of participants were associated with the data for the different measures to be combined, the lowest number of participants was inserted in CMA for all measures for that particular construct. This combining was not performed when one or more of the measures were a scale and the other or others were one or more separate items. In this case only the data for the scale or scales were used.

\section{Results}

Sample characteristics, the average weighted Hedges' $g$ and associated $95 \%$ confidence intervals as well as the results for the Q-test for heterogeneity and $I^{2}$ are presented in Table 5.

\subsection{Effectiveness}

The average weighted Hedges' $g$ for objective effectiveness was significantly positive and in the small to medium range (see also Fig. 1). Also for subjective effectiveness a positive, small to medium effect was found (see also Fig. 2). The heterogeneity in the effect sizes was significant for both types of effectiveness. For objective effectiveness, a large percentage of the observed variance was estimated to be due to heterogeneity (and not due to sampling error), and for subjective effectiveness a moderate percentage. The heterogeneity can also be seen in the forest plots in Figs. 1 and 2. In the section on moderator analyses we will explore for the moderator variables whether they are associated with the magnitude of the effect sizes for objective effectiveness.

Table 5

\begin{tabular}{|c|c|c|c|c|c|}
\hline Concept & $\begin{array}{l}\text { \# Effect sizes } \\
\text { (\# articles) }\end{array}$ & $\begin{array}{l}\# \\
\text { Students }\end{array}$ & $\begin{array}{l}\text { Average weighted } \\
\text { Hedges' g }(95 \% C I)\end{array}$ & $Q(p)$ & $I^{2}$ \\
\hline Objective effectiveness & $24(24)$ & 4155 & $0.34(0.17-0.52)$ & $139.60(<.01)$ & $83.52 \%$ \\
\hline Subjective effectiveness & $11(11)$ & 950 & $0.27(0.06-0.47)$ & $22.93(.01)$ & $56.39 \%$ \\
\hline Satisfaction & $30(30)$ & 3574 & $0.11(-0.01$ to 0.22$)$ & $67.29(<.01)$ & $56.90 \%$ \\
\hline Investment evaluations & $4(4)$ & 312 & $-1.04(-1.98$ to -0.10$)$ & $35.29(<.01)$ & $91.50 \%$ \\
\hline
\end{tabular}

Descriptives and the results of the Q-test for heterogeneity for each of the included concepts. 
Study name

Yapici \& Akbayin (2012)

Adileh (2012)

Yang (2012)

Kavadella et al. (2012)

Sung et al. (2008)

Atici \& Polat (2010)

Arroyo-Morales et al. (2012)

Lim et al. (2008)

Chandra \& Lloyd (2008)

Vernadakis et al. (2011)

Neumann \& Hood (2009)

Jia et al. (2012)

Chandra \& Watters (2012)

Riffell \& Merrill (2005)

Sadaghiani (2011)

Gutierrez \& Russo (2005)

Cakiroglu (2012)

Forte \& Root (2011)

Anderson \& May (2010)

Perkins et al. (2012)

Kocoglu et al. (2011)

Krawiec et al. (2005)

York (2008)

Delialioglu \& Yildirim (2008)
Hedges's

g

1.54

1.03

0.96

0.87

0.74

0.65

0.57

0.47

0.39

0.32

0.32

0.31

0.25

0.21

0.20

0.11

0.08

0.08

0.05

$-0.05$

$-0.08$

$-0.11$

$-0.36$

$-0.59$

0.34
Standard error

0.22
0.16
0.20
0.30

0.30
0.31

0.31
0.36

0.31

0.19

$0.09232 \quad 210$

$\begin{array}{lll}0.16 & 102 \quad 70\end{array}$

$0.28 \quad 27 \quad 25$

$0.20 \quad 47 \quad 49$

$\begin{array}{lll}0.23 & 48 \quad 32\end{array}$

$0.09230 \quad 246$

$0.24 \quad 29 \quad 40$

$0,32 \quad 18 \quad 20$

$\begin{array}{lll}0.18 & 61 & 64\end{array}$

$\begin{array}{lll}0.25 & 37 & 27\end{array}$

$0.29 \quad 16 \quad 45$

$0.04 \quad 817 \quad 809$

$0.40 \quad 8 \quad 23$

$\begin{array}{lll}0.26 & 27 & 31\end{array}$

$0.36 \quad 13 \quad 18$

$\begin{array}{lll}0.28 & 26 & 24\end{array}$

0.09
Hedges's g and $95 \% \mathrm{Cl}$
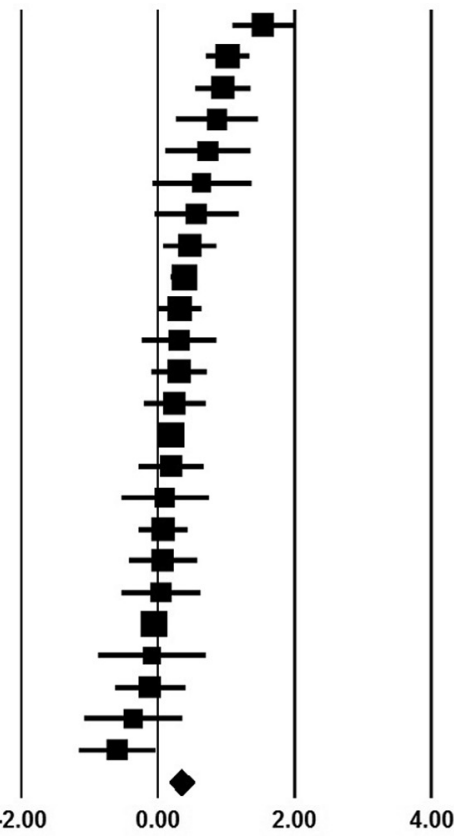

Favours BI

Favours $\mathrm{f} 2 \mathrm{f}$

Fig. 1. Forest plot for objective effectiveness with Hedges' $\mathrm{g}, \mathrm{SE}$ and $\mathrm{n}$ in both conditions for each included study.

\section{Study name}

$\begin{array}{lrrrr} & \begin{array}{c}\text { Hedges's } \\ \text { g }\end{array} & \begin{array}{c}\text { Standard } \\ \text { error }\end{array} & \text { Bl } & \text { F2f } \\ \text { Arroyo-Morales et al. (2012) } & 0.97 & 0.31 & 22 & 22 \\ \text { Korkmaz \& Karakuş (2009) } & 0.65 & 0.27 & 28 & 29 \\ \text { Woltering et al. (2009) } & 0.56 & 0.17 & 74 & 71 \\ \text { Feist et al. (2013) } & 0.36 & 0.18 & 119 & 45 \\ \text { Forte \& Root (2011) } & 0.33 & 0.22 & 41 & 38 \\ \text { Neumann \& Hood (2009) } & 0.23 & 0.27 & 27 & 25 \\ \text { Chen \& Jones (2007) } & 0.17 & 0.21 & 58 & 38 \\ \text { Carbonaro et al. (2008) } & 0.05 & 0.31 & 19 & 22 \\ \text { York (2008) } & -0.04 & 0.40 & 11 & 12 \\ \text { Hsu \& Hsieh (2011) } & -0.16 & 0.14 & 88 & 113 \\ \text { Sung et al. (2008) } & -0.18 & 0.28 & 24 & 24 \\ & 0.27 & 0.11 & & \end{array}$

\section{Hedges's $\mathrm{g}$ and $95 \% \mathrm{Cl}$}
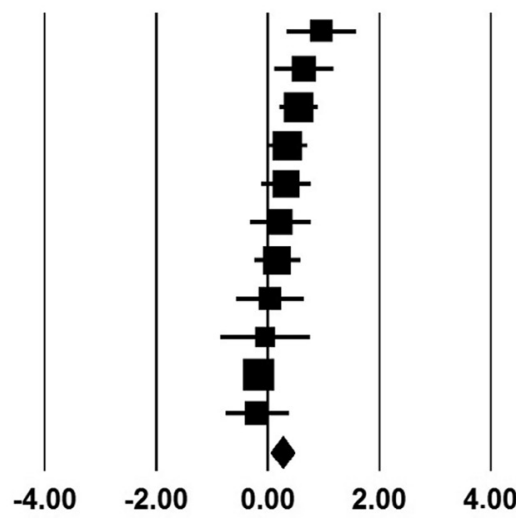

Favours f2f

Favours BI

Fig. 2. Forest plot for subjective effectiveness with Hedges' g, SE and $n$ in both conditions for each included study. 
A histogram, boxplot and standardized residuals for objective effectiveness showed that the effect size based on Yapici and Akbayin (2012) was the most deviant. Analyses with one study removed in CMA showed that Hedges' $g$ without this study was 0.29 (95\% $C I=0.13-0.45)$. So, deletion of this study did not have a large impact. This showed that the average effect size for objective effectiveness is not severely influenced by outliers. Based on the histogram and boxplot of the effect sizes for subjective effectiveness, none of the effect sizes could be defined as an outlier. According to the standardized residuals the effect size based on Arroyo-Morales et al. (2012) was the most deviant, although the standardized residual was even for this effect size lower than 2. One-study-removed analyses revealed that the average weighted effect size, after removing Arroyo-Morales et al. (2012), was 0.21 (95\% CI=0.02-0.41). So, removing this study did not change the results much, which implies that the effect of outliers was limited. The skewness and kurtosis of the effect size distribution for objective effectiveness were .56 and .82 and for subjective effectiveness 0.58 and -0.17 . So, these distributions were not very deviant from normal distributions.

\subsection{Satisfaction}

For satisfaction, a non-significant trivial average effect size was found. Additionally, significant heterogeneity was found. $I^{2}$ indicated that a moderate percentage of the observed variance could be considered to be due to heterogeneity rather than due to sampling error. In the forest plot presented in Fig. 3, it can also be seen that the effect sizes varied. In the section on moderator analyses, results are presented for tests investigating for the moderator variables whether they were associated with the magnitude of the effect sizes.

The standardized residuals revealed that the effect size based on Krawiec, Salter, and Kay (2005) was the most deviant. With one-study-removed analyses in CMA it was found that Hedges' $g$ without this study increases to $0.13(95 \% \mathrm{Cl}=0.02-$ $0.24)$. This implies that the results did not change much when this study was removed. The next most deviant effect size was the one based on Kumrow (2007). This effect size also appeared to be deviant in the boxplot and histogram. However, this was a positive effect size in contrast to the effect size based on Krawiec et al. (2005). Hence, the effect of removing this study would counteract the effect of removing Krawiec et al. (2005). Besides, the standardized residual for Kumrow (2007)

\begin{tabular}{|c|c|c|c|c|}
\hline \multicolumn{5}{|l|}{ Study name } \\
\hline & $\underset{\mathrm{g}}{\text { Hedges's }}$ & $\begin{array}{l}\text { Standard } \\
\text { error }\end{array}$ & $\mathrm{BI}$ & $\mathrm{F} 2 \mathrm{~F}$ \\
\hline Kumrow (2007) & 0.94 & 0.36 & 18 & 15 \\
\hline Forte \& Root (2011) & 0.59 & 0.23 & 41 & 38 \\
\hline Lim et al. (2008) & 0.58 & 0.19 & 40 & 82 \\
\hline Woltering et al. (2009) & 0.51 & 0.17 & 74 & 71 \\
\hline Feist et al. (2013) & 0.48 & 0.18 & 116 & 42 \\
\hline Vernadakis et al. (2012) & 0.42 & 0.29 & 24 & 22 \\
\hline Pereira et al. (2007) & 0.37 & 0.21 & 49 & 41 \\
\hline Taradi et al., (2005) & 0.27 & 0.20 & 37 & 84 \\
\hline George-Palilonis \& Filak (2009) & 0.26 & 0.16 & 117 & 54 \\
\hline Lancaster et al. (2012) & 0.22 & 0.30 & 29 & 18 \\
\hline Newhouse et al. (2013) & 0.22 & 0.31 & 17 & 24 \\
\hline Salyers (2005) & 0.20 & 0.28 & 24 & 25 \\
\hline Cole \& Robertson (2006) & 0.17 & 0.10 & 353 & 142 \\
\hline Lapidus et al. (2012) & 0.15 & 0.32 & 21 & 17 \\
\hline Bartini (2008) & 0.14 & 0.34 & 17 & 17 \\
\hline Larson \& Sung (2009) & 0.09 & 0.18 & 59 & 60 \\
\hline Kavadella et al. (2012) & 0.09 & 0.29 & 24 & 23 \\
\hline Martinez-Caro \& Campuzano-Bolarin (2011) & 0.07 & 0.07 & 370 & 410 \\
\hline Sung et al. (2008) & 0.06 & 0.29 & 24 & 24 \\
\hline Arroyo-Morales et al. (2012) & 0.06 & 0.30 & 22 & 22 \\
\hline Chen \& Jones (2007) & 0.03 & 0.21 & 58 & 38 \\
\hline Edwards et al., (2012) & -0.15 & 0.27 & 29 & 26 \\
\hline Neumann \& Hood (2009) & -0.18 & 0.27 & 27 & 25 \\
\hline Carbonaro et al. (2008) & -0.18 & 0.29 & 19 & 27 \\
\hline Delialioglu \& Yildirim (2008) & -0.20 & 0.28 & 26 & 24 \\
\hline Hsu \& Hsieh (2011) & -0.20 & 0.14 & 88 & 113 \\
\hline Grasl et al. (2012) & -0.35 & 0.13 & 117 & 119 \\
\hline Senn (2008) & -0.40 & 0.33 & 13 & 32 \\
\hline Krawiec et al. (2005) & -0.66 & 0.29 & 24 & 26 \\
\hline \multirow[t]{2}{*}{ Salyers (2007) } & -0.68 & 0.34 & 22 & 14 \\
\hline & 0.11 & 0.06 & & \\
\hline
\end{tabular}

Hedges's g and $95 \% \mathrm{Cl}$

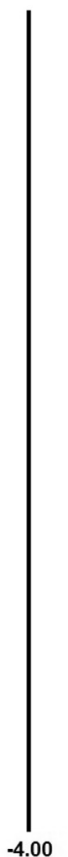

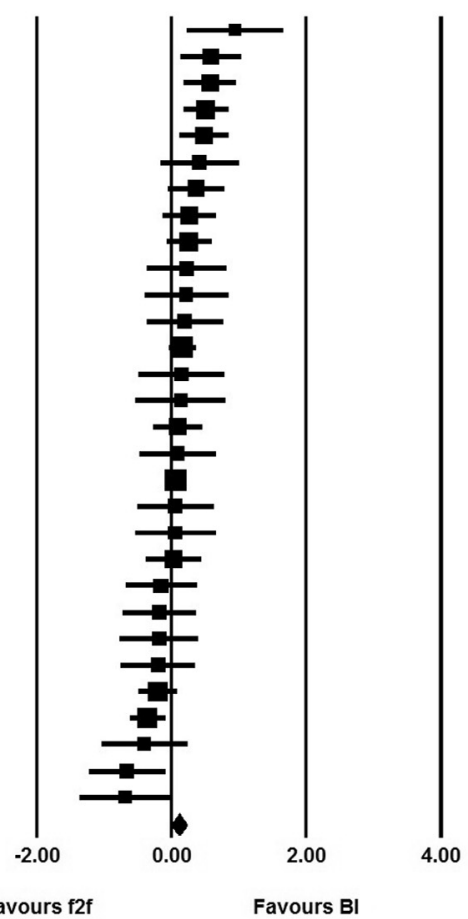

Fig. 3. Forest plot for satisfaction with Hedges' g, SE and $n$ in both conditions for each included study. 


\section{Study name}

Arroyo-Morales et al. (2012)

George-Palilonis \& Filak (2009)

Krawiec et al. (2005)

Senn (2008)

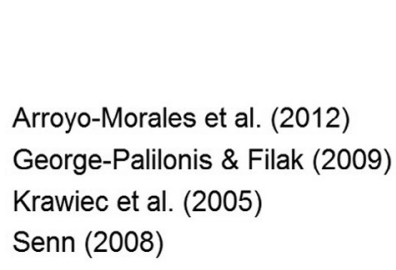

Hedges's g and $95 \% \mathrm{Cl}$

$\begin{array}{cccc}\begin{array}{c}\text { Hedges's } \\ \mathbf{g}\end{array} & \begin{array}{c}\text { Standard } \\ \text { error }\end{array} & \text { bl } & \text { f2f } \\ 0.01 & 0.30 & 22 & 22 \\ -0.37 & 0.16 & 117 & 54 \\ -1.55 & 0.32 & 24 & 26 \\ -2.42 & 0.40 & 14 & 33 \\ -1.04 & 0.48 & & \end{array}$

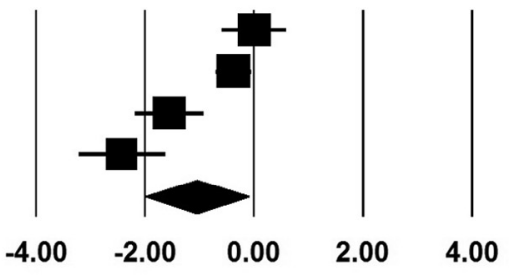

Favours f2f Favours BI

Fig. 4. Forest plot for investment evaluations with Hedges' g, SE and $\mathrm{n}$ in both conditions for each included study.

was below 2. The skewness and kurtosis of the effect size distribution were -0.15 and 0.39 . So, the distribution was not very deviant from a normal distribution.

\subsection{Investment evaluations}

A significant negative average effect size for investment evaluations was found. It was a large effect, but this effect size was based on only four studies. Additionally, significant heterogeneity was found and a large percentage of the observed variance could be considered to be due to heterogeneity (see also Fig. 4).

\subsection{Moderator analyses for objective effectiveness and satisfaction}

The test results for the moderator analyses for objective effectiveness and satisfaction are presented in Table 6. Table 7 shows for which categories of the moderator variables sufficient data were available to compare them with each other. Only one of the potential moderator variables, that is, quizzes, had a significant relation with the effect sizes for objective effectiveness and for satisfaction. It appeared that the average effect size for satisfaction was higher when quizzes were available in the blended learning condition, but no quizzes were available for the control condition $(g=.27, S E=.08)$ than when no quizzes were available for both conditions ( $g=.05, S E=.07$ ). Two pairwise comparisons were conducted to further explore this significant finding for objective effectiveness. The alpha level for these two pairwise comparisons was set at 0.025 . It was found that the average effect size for objective effectiveness was higher, but not significantly ( $p=.07$ ), for the 13 studies with quizzes in the blended learning condition but no quizzes (or no information on quizzes) for the control condition ( $g=0.56$, $S E=0.12$ ) than for the 6 studies with no quizzes (or no information on quizzes) for both conditions $(g=0.13, S E=0.20)$. However, the average effect size for objective effectiveness was significantly higher $(p=.01)$ for the 13 studies with quizzes in the blended learning condition but no quizzes for the control condition $(g=0.56, S E=0.12)$ than for 5 studies with quizzes in both conditions ( $g=-0.09, S E=0.22$ ). The comparison of studies with no quizzes (or no information on quizzes) for both conditions and studies with quizzes in both conditions does not reveal information with regard to blended learning. Therefore, this pairwise comparison was not conducted.

Table 6

Test results for the moderator analyses for objective effectiveness and for satisfaction.

\begin{tabular}{|c|c|c|c|c|c|c|}
\hline \multirow[t]{2}{*}{ Factor } & \multicolumn{3}{|c|}{ Objective effectiveness } & \multicolumn{3}{|c|}{ Satisfaction } \\
\hline & QBetween & $d f$ & $P$ & $Q_{\text {Between }}$ & $d f$ & $p$ \\
\hline Allocation & 0.08 & 1 & .77 & 1.04 & 1 & .31 \\
\hline Educational level & 2.54 & 1 & .11 & - & - & - \\
\hline Subject matter & $<.01$ & 1 & .93 & 5.13 & 2 & .08 \\
\hline Duration & 1.81 & 1 & .18 & 0.07 & 1 & .79 \\
\hline Communication in the online part & 1.53 & 2 & .47 & 2.08 & 1 & .15 \\
\hline Quizzes & 8.38 & 2 & .02 & 4.85 & 1 & .03 \\
\hline
\end{tabular}


Table 7

Included categories of the moderator variables with the associated numbers of studies.

\begin{tabular}{llll}
\hline Moderator variables & Categories & $\begin{array}{l}\text { Objective } \\
\text { effectiveness }\end{array}$ & Satisfaction \\
\hline Allocation & Selected & 6 studies & 8 studies \\
Educational level & Groups & 10 studies & 17 studies \\
& K-12 & 5 studies & \\
Subject matter & Post-secondary & 19 studies & \\
& Beta & 11 studies & 6 studies \\
& Gamma & & 10 studies \\
Duration & Health related & 5 studies & 14 studies \\
& Long & 9 studies & 15 studies \\
Communication in the online part & Short & 12 studies & 10 studies \\
& Both & 7 studies & 9 studies \\
& Asynchronous & 11 studies & 17 studies \\
& No & 6 studies & \\
& Both & 5 studies & 12 studies \\
& Blended only & 13 studies & 15 studies \\
\hline
\end{tabular}

\section{Discussion}

Significantly positive average effect sizes in the small to medium range were found for both objective and subjective effectiveness and a trivial non-significant effect size was found for satisfaction. So, the effectiveness of blended learning was on average better than for more traditional learning. Additionally, on average students are equally satisfied with both types of learning. A large negative effect size was found for investment evaluations. This implies that on average, students perceived blended learning to be more demanding and/or less appropriate with regard to the required investments compared with more traditional learning. However, the latter average was only based on four studies and should, therefore, be interpreted with care. Nevertheless, it gives a first indication for the plausibility of the suggestion by Sitzmann et al. (2006) that blended learning might be more demanding than more traditional education. The small to medium positive findings for effectiveness of blended learning seem to have a cost in terms of the investments and/or the appropriateness of the investments required in blended learning.

Although on average positive effects for effectiveness and a neutral effect for attractiveness were found, there were large differences between the studies and even examples of negative effects. For required investment also large differences between studies were found. Such large differences in effects between studies imply that putting some materials or activities online does not always lead to neutral or positive results.

A few of the many aspects on which studies differ from each other were included as moderator variables. For quizzes significant effects on effectiveness and attractiveness were found. This implies that blended learning environments with quizzes were in general more effective and attractive. Because of the way the data are analyzed, it is not possible to infer whether these relations are causal (Borenstein et al., 2009).

For the other investigated factors, i.e. allocation, level of education, subject matter, duration and kind of online communication, no significant results were found. However, the power of moderator analyses is often quite low (Borenstein et al., 2009). So, it cannot be excluded that associations between these other factors and effectiveness and/or satisfaction exist, but were not found.

\subsection{Comparison of our results with those of other meta-analyses}

An average effect size in the small to medium range for effectiveness is in line with the results of previous metaanalyses (Bernard et al., 2014; Means et al., 2013; Schmid et al., 2014; Sitzmann et al., 2006; Tamim et al., 2011). With regard to satisfaction, the results of previous meta-analyses ranged from a trivial negative effect size (Sitzmann et al., 2006) to a small to medium positive effect size (Schmid et al., 2014). Our trivial positive effect size fits in this range. So despite another approach with regard to the description of blended learning, the inclusion of all levels of education, the use of only more recent studies and stricter requirements for measures to be considered as assessing satisfaction, quite similar results were found in these meta-analyses as in previous meta-analyses. This implies that the results from these previous studies are replicable. It also shows that different approaches with regard to these issues do not largely affect the results.

In our meta-analyses, quizzes appeared to be a significant moderator. When quizzes were available in blended learning, but not in the more traditional condition, the effectiveness was higher than when quizzes were available in both conditions and satisfaction was higher than when no quizzes were present in both conditions. Previous meta-analyses examined similar moderator variables. However, their moderator variables included more than only quizzes and their moderator analyses were not or not only focused on blended learning. Sitzmann et al. (2006) tested the effects of practice and feedback in moderator analyses for the effect sizes for learning outcomes of fully online learning compared with more traditional learning. Their variable 'practice' was broader as our variable quizzes because it included in addition to practice exams, which 
could be a type of quiz or self-test, also other instructional aspects. Both practice and feedback appeared to be significant moderators, which is in line with our findings. Means et al. (2013) examined the effects of opportunity to practice and feedback provided in online and blended learning conditions in moderator analyses for a combination of effect sizes for online and more traditional learning and blended and more traditional learning. In contrast to the findings of our moderator analyses and those of Sitzmann et al. (2006), they did not find significant effects of the moderators. This implies that in their analyses no significant differences were found between studies differing with regard to the presence or absence of opportunities to practice or to receive feedback in the experimental learning environments.

\subsection{Limitations}

Studies can vary on many aspects, besides the aspects examined as moderators. Studies differ also on whether they report information about those other aspects and what they report about them. It was yet not uncommon for one or even both conditions to be poorly described. Consequently, scoring particular aspects was difficult or even impossible (cf. Bernard et al., 2014; Means et al., 2013; Sitzmann et al., 2006) and hence also to examine whether those aspects are significant moderators. This also hinders studying what has caused the substantial heterogeneity, and whether this heterogeneity was mainly due to methodological problems or differences in how blended learning was implemented in different studies.

Many studies had some methodological problems, but our meta-analyses can only reveal what is found by these studies. For example, only three articles used an experimental research design and sample sizes were also small in a number of studies. For the studies included for objective effectiveness, which did not randomly assign participants, we required a pre-test, GPA, or other a priori competence test to be present to judge the comparability of the groups before the study for inclusion in our meta-analysis. This requirement could not be made for the other concepts, which could have biased our results.

The analysis methods that were used assume that the data from the students are independent from each other. However, in some studies students had to work together or results from different courses, groups or classes were combined, which leads to some interdependency between the data. Another assumption made in our analyses is that a latent continuous aspect was underlying rating scales, even when only one item with a 3- or 4-point rating scale was used. Furthermore, statistics for gain and post-test scores were mixed.

Due to different factors, it is more likely that a study is written down and published in a peer-reviewed journal, when it shows not too small positive effects (e.g., Borenstein et al., 2009, Clark, 1983; Lipsey \& Wilson, 2001). Additionally, within studies a related type of bias could have occurred. It is, therefore, possible that information with regard to groups and variables for which positive effects are found is more likely to be reported in sufficient detail to be included. It cannot be excluded that these different types of publication bias have led to an upward bias. Besides publication bias, biases due to a novelty effect (e.g., Bracht \& Glass, 1968; Chandra \& Lloyd, 2008; Clark, 1983; Martínez-Caro \& Campuzano-Bolarín, 2011), a Hawthorne effect (Arroyo-Morales et al., 2012; Bracht \& Glass, 1968; Neumann \& Hood, 2009) or a halo effect (Chen \& Jones, 2007) could have affected the results.

By deleting studies in which large simultaneous changes in pedagogy and/or learning activities were implemented together with the change to blended learning, we tried to reduce the amount of confounding between blended learning and learning activities. However, even when those most extreme confounders are deleted, conditions are still not always comparable in learning activities, and this might have influenced the results. Studies were also deleted when the online part in the blended condition was only an addition to the more traditional education. However, even when the online parts are a substitution for some part of the education in more traditional learning, differences in time-on-task cannot be excluded as a factor underlying effects of blended learning on effectiveness, student satisfaction and evaluations of required investments. When the increase in effectiveness is due to a shift toward a more active and learner-centered approach, due to the investment of more effort in the instructional design, due to increased time-on-task or due to better adaptation to the needs of students, it is, however, disputable whether it is the implementation of blended learning, the learning activities used, or their combination which has led to the positive results (cf. Means et al., 2013; see also Clark, 1983, 1994; Cobb, 1997; Kozma, 1991, 1994). On the other hand, some authors (e.g., Graham \& Robison, 2007) state that it is important to use blended learning to transform pedagogy and use it not only for practical reasons in the sense of increased access and resource management. So by excluding studies with too large simultaneous changes, it might be that we do not reveal the full potential of blended learning either. Additionally, in some studies it was maybe even intended to increase time-on-task (cf., Means et al., 2013). Sung, Kwon, and Ryu (2008) replaced, for example, 7.5 hours of lectures with 20 hours of e-learning. On the other hand, in Edwards et al. (2012) study time for blended learning was maybe even less. This issue is about the balance between internal and external validity (Abrami \& Bernard, 2006; Bernard et al., 2014). By trying to separate the effects of blended learning and learning activities, it was aimed to improve the internal validity of the meta-analysis. From a researcher's point of view, internal validity is important. From this point of view it might be a limitation that it was not possible to completely separate the effects of blended learning and the effects of learning activities, pedagogy or time-on-task. From a practitioner's point of view, external validity is important. This validity is diminished by trying to separate these effects. In practice, blended learning encourages the use of the capabilities offered by computers, for example through the use of more, authentic, varied and different instructional materials and innovative learning activities. Blended learning might even be used to transform pedagogy (e.g., Graham \& Robison, 2007). For a practitioner it is a limitation from our study that the external validity was limited and results are summarized only for studies on blended learning in which the learning activities and pedagogy did not change too much. 


\subsection{Future directions}

The majority of the articles studied university students. This underrepresentation of studies with other types of learners limits the generalizability of the results to other groups (cf. Jaggars \& Bailey, 2010; Lipsey \& Wilson, 2001). Underrepresentation of other populations than university students was also reported by Drysdale et al. (2013) and Halverson, Graham, Spring, and Drysdale (2012).

Our meta-analyses do not give information about whether blended learning leads to the expected improvements in access and resource management and whether other stakeholders (i.e., teachers, instructional designers, technical staff or other faculty) are satisfied with blended learning. These topics might be difficult to examine with comparative studies. Hence, they are almost never examined in such types of studies. Similarly, other reviews (Drysdale et al., 2013; Graham, 2013; Halverson et al., 2012, 2014) also suggest that more research is needed with regard to these issues (see also Jaggars \& Bailey, 2010).

The found large variability in the effects on effectiveness, student satisfaction and evaluations of required investments implies that not all implementations of blended learning positively affect effectiveness and student satisfaction or negatively affect evaluations of required investments. The finding that the inclusion of quizzes, tests or self-assessments has a positive effect on effectiveness and attractiveness shows the importance of systematic, careful design of blended learning. To inform instructional designers and teachers about how to design a blended learning environment, studies which examine what are the critical features in a successful design of blended learning are needed. Especially suited for this purpose are studies which compare the effects on effectiveness, satisfaction and evaluations of required investments of two or more blended learning environments differing on particular features (cf. Bernard et al., 2009; Cook, 2009; Mayer, 2011; Tamim et al., 2011; Schmid et al., 2014).

Another topic which would be interesting for future studies to explore in more detail is the effect of the quizzes as a positive feature in blended learning. It would be interesting to compare blended learning environments with different types of quizzes with regard to the learning outcomes and student satisfaction. Additionally, it would be interesting to examine whether the types of quizzes which are most effective and attractive in blended learning differ from those which are most effective and attractive in a more traditional learning environment. Finally, it is known that spacing of testing (Bangert-Drowns et al., 1991; Pashler et al., 2007; Roediger \& Karpicke, 2006) and learning activities (Budé et al., 2011; Dempster, 1988; Smith \& Rothkopf, 1984) positively affects learning. However, in most studies, the same material is learned or tested at multiple occasions, while in studies on blended learning, and in education in general, a different content is learned each week. It would be interesting to examine whether encouraging students to space learning from different contents across multiple occasions has similar positive effects. This is yet a topic which is only scarcely examined.

\subsection{Practical implications}

On average, blended learning was somewhat more effective and about equally attractive. So, blended learning was not systematically less effective and attractive than more traditional learning, rather somewhat more effective. This means that practical advantages, like increased access and resource management, might be good reasons to implement blended learning. However, future studies should examine whether the high expectations with regard to these advantages are met (cf. Jaggars \& Bailey, 2010).

The results of four studies suggest that students perceive blended learning as more demanding or being less appropriate in the investments required. This might be an intended effect, when blended learning was implemented to improve learning outcomes by providing learners with more instructional materials and/or having them to spend more time-on-task (Means et al., 2013). However, it could also indicate a risk that instructional designers or teachers make blended learning more demanding (cf. Graham \& Robison, 2007; Kaleta et al., 2007). On the other hand, students may underestimate the amount of work in blended learning (Kaleta et al., 2007) or perceive face-to-face meetings not as work, but do perceive spending the same amount of time on studying at home as work (Aycock et al., 2002). These incorrect expectations and perceptions may be alternative explanations for the results for investment evaluations. Nevertheless, the investments required of the students for blended learning should be carefully considered during its design.

The large variability in the effects on effectiveness, student satisfaction and evaluations of required investments also suggests that not all implementations of blended learning had similar effects on these aspects. So, the high expectations in terms of educational improvement are on average met, but not always. This implies that simply putting materials online does not automatically lead to positive results. It is important to thoughtfully consider and rethink the instructional design, when implementing blended learning. Quizzes or other regular tests are suggested to be associated with more effective and more attractive blended learning. This suggests that quizzes or other regular tests are an important factor in the effectiveness and attractiveness of blended learning. They are also easy to include in a blended learning environment and they can score the answers of students and provide the students with feedback (e.g., Cole \& Robertson, 2006; Jia et al., 2012; Riffell \& Sibley, 2005).

\subsection{Theoretical background for the positive effects of quizzes on learning outcomes}

In our study positive effects of quizzes, tests and self-assessments on effectiveness and satisfaction of quizzes are found. For the effects of quizzes on learning outcomes already a firm theoretical background exists. When learners make a test, 
they retrieve information from memory, which makes the path to that information in memory stronger, with the consequence that the information can be more easily retrieved on the next occasion (e.g., Dirkx et al., 2014; Pashler et al., 2007). Additionally, feedback on the quizzes often gives useful information on correct answers (Butler, Karpicke, \& Roediger, 2008; Butler \& Roediger, 2008) as well as an image of the mastery of the content by the students (Butler et al., 2008; Butler \& Roediger, 2008; Butler \& Winne, 1995; Pashler et al., 2007; Roediger \& Karpicke, 2006). This information on the mastery of the content is useful in determining which aspects should be given renewed attention (Pashler et al., 2007; Roediger \& Karpicke, 2006). Furthermore, when given frequently, quizzes maybe also help students in spacing their learning activities (Mawhinney et al., 1971), which might affect learning outcomes positively (Budé et al., 2011; Dempster, 1988; Smith \& Rothkopf, 1984). Finally, when students are well prepared for face-to-face meetings, for example, because they studied for regular quizzes, these meetings can be used to a larger extent for active learning activities (Bartini, 2008).

\subsection{General conclusion}

In sum, blended learning is on average somewhat more effective than more traditional learning, but equally attractive, although it is possible that blended learning also has a cost in terms of requiring more investments. Effects on effectiveness, student satisfaction and evaluations of required investments differed much between studies. Thus, averages do not apply to all implementations of blended learning. Fear for deterioration of the effectiveness or attractiveness of education should not be a reason to disregard the implementation of blended learning, but blended learning also does not automatically improve education. When thoughtfully designed, blended learning has potential. The inclusion of quizzes is a factor contributing to a successful implementation of blended learning.

\section{Acknowledgements}

This research was funded by Kennisnet, the knowledge center for information and communication technologies and education in The Netherlands.

\section{References}

*Indicates references used in the analyses.

Abrami, P. C., \& Bernard, R. M. (2006). Research on distance education: In defense of field experiments. Distance Education, $27,5-26$.

*Adileh, M. (2012). Teaching music as a university elective course through e-learning. Australian Journal of Music Education, 1, 71-79.

Allen, I. E., Seaman, J., \& Garrett, R. (2007). Blending in. The extent and promise of blended education in the United States. Needham, MA: Sloan-C.

*Anderson, K., \& May, F. A. (2010). Does the method of instruction matter? An experimental examination of information literacy instruction in the online, blended, and face-to-face classrooms. Journal of Academic Librarianship, 36(6), 495-500.

*Arroyo-Morales, M., Cantarero-Villanueva, I., Fernández-Lao, C., Guirao-Piñeyro, M., Castro-Martín, E., \& Díaz-Rodríguez, L. (2012). A blended learning approach to palpation and ultrasound imaging skills through supplementation of traditional classroom teaching with an e-learning package. Manual Therapy, 17(5), 474-478.

*Atici, B., \& Polat, O. C. (2010). Influence of the online learning environments and tools on the student achievement and opinions. Educational Research and Reviews, 5, 455-464.

Aycock, A., Garnham, C., \& Kaleta, R. (2002). Lessons learned from the hybrid course project. Teaching with Technology Today, 8(6).

Bangert-Drowns, R. L., Kulik, J. A., \& Kulik, C.-L. C. (1991). Effects of frequent classroom testing. The Journal of Educational Research, 85, 89-99.

*Bartini, M. (2008). An empirical comparison of traditional and web-enhanced classrooms. Journal of Instructional Psychology, 35(1), 3-11.

Bernard, R. M., Abrami, P. C., Borokhovski, E., Wade, C. A., Tamim, R. M., Surkes, M. A., et al. (2009). A meta-analysis of three types of interaction treatments in distance education. Review of Educational Research, 79, 1243-1289.

Bernard, R. M., Borokhovski, E., Schmid, R. F., Tamim, R. M., \& Abrami, P. C. (2014). A meta-analysis of blended learning and technology use in higher education: From the general to the applied. Journal of Computing in Higher Education, 26, 87-122.

Bonk, C. J., Kim, K.-J., \& Zeng, T. (2006). Future directions of blended learning in higher education and workplace learning settings. In C. J. Bonk \& C. R. Graham (Eds.), The handbook of blended learning: Global perspectives, local designs (pp. 550-567). San Francisco, CA: John Wiley \& Sons.

Borenstein, M., Hedges, L. V., Higgins, J. P. T., \& Rothstein, H. R. (2009). Introduction to meta-analysis. Chichester, UK: Wiley.

Bracht, G. H., \& Glass, G. V. (1968). The external validity of experiments. American Educational Research Journal, 5, 437-474.

Budé, L., Imbos, T., Van de Wiel, M. W., \& Berger, M. P. (2011). The effect of distributed practice on students' conceptual understanding of statistics. Higher Education, 62, 69-79.

Butler, A. C., Karpicke, J. D., \& Roediger, H. L. (2008). Correcting a meta-cognitive error: Feedback increases retention of low-confidence correct responses. Journal of Experimental Psychology. Learning, Memory, and Cognition, 34, 918-928.

Butler, A. C., \& Roediger, H. L. (2008). Feedback enhances the positive effects and reduces the negative effects of multiple-choice testing. Memory \& Cognition, $36,604-616$.

Butler, D. L., \& Winne, P. H. (1995). Feedback and self-regulated learning: A theoretical synthesis. Review of Educational Research, 65, $245-281$.

${ }^{*}$ Cakiroglu, U. (2012). Comparison of novice programmers' performances: Blended versus face-to-face. Turkish Online Journal of Distance Education, 13(3), 135-151.

*Carbonaro, M., King, S., Taylor, E., Satzinger, F., Snart, F., \& Drummond, J. (2008). Integration of e-learning technologies in an interprofessional health science course. Medical Teacher, 30(1), 25-33.

*Chandra, V., \& Lloyd, M. (2008). The methodological nettle: ICT and student achievement. British Journal of Educational Technology, 39, 1087-1098.

*Chandra, V., \& Watters, J. J. (2012). Re-thinking physics teaching with web-based learning. Computers \& Education, 58(1), 631-640.

${ }^{*}$ Chen, C. C., \& Jones, K. T. (2007). Blended learning vs. traditional classroom settings: Assessing effectiveness and student perceptions in an MBA accounting course. Journal of Educators Online, 4(1).

Clark, R. E. (1983). Reconsidering research on learning from media. Review of Educational Research, 53, 445-459.

Clark, R. E. (1994). Media will never influence learning. ETR\&D, 42(2), 21-29.

Comprehensive Meta-Analysis (Version 2.2.064) (2011). [Computer software] Englewood, HJ: Biostat.

Cobb, T. (1997). Cognitive efficiency: Toward a revised theory of media. ETR\&D, 45(4), 21-35.

Cohen, J. (1988). Statistical power analysis for the behavioral sciences (2nd ed.). Hillsdale, NJ: Lawrence Earlbaum Associates. 
*Cole, J., \& Robertson, B. (2006). Using market segmentation to develop a large section, web-enhanced survey course. Innovate: Journal of Online Education, 2(4).

Cook, D. A. (2009). The failure of e-learning research to inform educational practice, and what we can do about it. Medical Teacher, 31 , $158-162$.

Costello, B., Lenholt, R., \& Stryker, J. (2004). Using Blackboard in library instruction: Addressing the learning styles of generations X and Y. The Journal of Academic Librarianship, 30, 452-460.

*Delialioglu, O., \& Yildirim, Z. (2008). Design and development of a technology enhanced hybrid instruction based on MOLTA model: Its effectiveness in comparison to traditional instruction. Computers \& Education, 51(1), 474-483.

Dempster, F. N. (1988). The spacing effect: A case study in the failure to apply thre results of psychological research. American Psychologist, 43, 627-634.

Dirkx, K. J. H., Kester, L., \& Kirschner, P. A. (2014). The testing effect for learning principles and procedures from texts. The Journal of Educational Research, $107,357-364$.

Drysdale, J. S., Graham, C. R., Spring, K. J., \& Halverson, L. R. (2013). An analysis of research trends in dissertations and theses studying blended learning. Internet and Higher Education, 17, 90-100.

*Edwards, G., Kitzmiller, R. R., \& Breckenridge-Sproat, S. (2012). Innovative health information technology training: Exploring blended learning. Computers, Informatics, Nursing, 30(2), 104-109.

*Feist, M., Ciccarelli, M., McFerron, B. A., \& Molleston, J. P. (2013). Methods and effects of a case-based pediatric gastroenterology online curriculum. Journal of Pediatric Gastroenterology and Nutrition, 56(2), 161-165.

*Forte, J. A., \& Root, V. (2011). To ITV or not to ITV: A comparison of hybrid and web-enhanced approaches to teaching a macro-course in human behavior in the social environment. Journal of Human Behavior in the Social Environment, 21(1), 82-96.

*George-Palilonis, J., \& Filak, V. (2009). Blended learning in the visual communications classroom: Student reflections on a multimedia course. Electronic Journal of e-Learning, 7(3), 247-256.

Graham, C. R. (2006). Blended learning systems: Definition, current trends and future directions. In C. J. Bonk \& C. R. Graham (Eds.), The handbook of blended learning: Global perspectives, local designs (pp. 3-21). San Francisco, CA: John Wiley \& Sons.

Graham, C. R. (2009). Blended learning models. In M. Khosrow-Pour (Ed.), Encyclopedia of Information Science and Technology (2nd ed., pp. 375-382). Hershey, PA: IGI Global.

Graham, C. R. (2013). Emerging practice and research in blended learning. In M. G. Moore (Ed.), Handbook of distance education (3rd ed., pp. 333-350). New York: Routledge.

Graham, C. R., \& Robison, R. (2007). Realizing the transformational potential of blended learning. Comparing cases of transforming blends and enhancing blends in higher education. In A. G. Picciano \& C. D. Dziuban (Eds.), Blended learning: Research perspectives (pp. 83-110). Needham, MA: Sloan-C.

*Grasl, M. C., Pokieser, P., Gleiss, A., Brandstaetter, J., Sigmund, T., Erovic, B. M., et al. (2012). A new blended learning concept for medical students in otolaryngology. Archives Otolaryngoly - Head \& Neck Surgery, 138(4), 358-366.

*Gutierrez, D., \& Russo, S. (2005). Comparing student performance, attitudes and preferences in an introduction to business course: Online, hybrid and traditional delivery methods - Who makes the "A" grade? College Teaching Methods \& Styles Journal, 1(3), 83-90.

Halverson, L. R., Graham, C. R., Spring, K. J., \& Drysdale, J. S. (2012). An analysis of high impact scholarship and publication trends in blended learning. Distance Education, 33, 381-413.

Halverson, L. R., Graham, C. R., Spring, K. J., Drysdale, J. S., \& Henrie, C. R. (2014). A thematic analysis of the most highly cited scholarship in the first decade of blended learning research. Internet and Higher Education, 20, 20-34.

Hedges, L. V. (1981). Distribution theory for Glass's estimator of effect size and related estimators. Journal of Educational Statistics, 6, 107-128.

Higgins, J. P. T., Thompson, S. G., Deeks, J. J., \& Altman, D. G. (2003). Measuring inconsistency in meta-analyses. BMJ (Clinical Research Ed.), 327, 557-560.

*Hsu, L. L., \& Hsieh, S. I. (2011). Effects of a blended learning module on self-reported learning performances in baccalaureate nursing students. Journal of Advanced Nursing, 67(11), 2435-2444.

Jaggars, S. S., \& Bailey, T. (2010). Effectiveness of fully online courses for college students: Response to a Department of Education meta-analysis. Community College Research Center, Columbia University.

*Jia, J., Chen, Y., Ding, Z., \& Ruan, M. (2012). Effects of a vocabulary acquisition and assessment system on students' performance in a blended learning class for English subject. Computers \& Education, 58(1), 63-76.

Kaleta, R., Skibba, K., \& Joosten, T. (2007). Discovering, designing and delivering hybrid courses. In A. G. Picciano \& C. D. Dziuban (Eds.), Blended learning: Research perspectives (pp. 111-144). Needham, MA: Sloan-C.

*Kavadella, A., Tsiklakis, K., Vougiouklakis, G., \& Lionarakis, A. (2012). Evaluation of a blended learning course for teaching oral radiology to undergraduate dental students. European Journal of Dental Education, 16(1), e88-e95.

Kim, K.-J., Bonk, C. J., \& Oh, E. (2008). The present and future state of blended learning in workplace learning settings in the United States. Performance Improvement, 47(8), 5-16.

${ }^{*}$ Kocoglu, Z., Ozek, Y., \& Kesli, Y. (2011). Blended learning: Investigating its potential in an English language teacher training program. Australasian Journal of Educational Technology, 27(7), 1124-1134.

*Korkmaz, Ö., \& Karakuş, U. (2009). The impact of blended learning model on student attitudes towards geography course and their critical thinking dispositions and levels. Turkish Online Journal of Educational Technology - TOJET, 8(4), 51-63.

Kozma, R. B. (1991). Learning with media. Review of Educational Research, 61, 179-211.

Kozma, R. B. (1994). Will media influence learning? Reframing the debate. ETR\&D, 42(2), 7-19.

Könings, K. D., Brand-Gruwel, S., \& Van Merriënboer, J. J. G. (2005). Towards more powerful learning environments through combining the perspectives of designers, teachers and students. British Journal of Educational Psychology, 75, 645-660.

Könings, K. D., Brand-Gruwel, S., Van Merriënboer, J. J. G., \& Broers, N. J. (2008). Does a new learning environment come up to students' expectations? A longitudinal study. Journal of Educational Psychology, 100, 535-548.

*Krawiec, S., Salter, D., \& Kay, E. J. (2005). A “hybrid” bacteriology course: The professor's design and expectations: The students' performance and assessment. Microbiology Education, 6, 8-13.

*Kumrow, D. E. (2007). Evidence-based strategies of graduate students to achieve success in a hybrid web-based course. Journal of Nursing Education, $46(3), 140-145$.

*Lancaster, J. W., Wong, A., \& Roberts, S. J. (2012). 'Tech' versus 'talk': A comparison study of two different lecture styles within a Master of Science nurse practitioner course. Nurse Education Today, 32(5), e14-e18.

*Lapidus, M., McCord, S. K., McCloskey, W. W., \& Kostka-Rokosz, M. D. (2012). Combined use of online tutorials and hands-on group exercises in bibliographic instruction for pharmacy students. Medical Reference Service Quarterly, 31(4), 383-399.

*Larson, D. K., \& Sung, C.-H. (2009). Comparing student performance: Online versus blended versus face-to-face. Journal of Asynchronous Learning Networks, $13(1), 31-42$.

${ }^{*}$ Lim, J., Kim, M., Chen, S. S., \& Ryder, C. E. (2008). An empirical investigation of student achievement and satisfaction in different learning environments. Journal of Instructional Psychology, 35(2), 113-119.

Lipsey, M. W., \& Wilson, D. B. (2001). Practical meta-analysis. Thousand Oaks, CA: Sage Publications.

*Martínez-Caro, E., \& Campuzano-Bolarín, F. (2011). Factors affecting students' satisfaction in engineering disciplines: Traditional vs. blended approaches. European Journal of Engineering Education, 36(5), 473-483.

Mawhinney, V. T., Bostow, D. E., Laws, D. R., Blumenfeld, G. J., \& Hopkins, B. L. (1971). A comparison of students studying-behavior produced by daily, weekly, and three-week testing schedules. Journal of Applied Behavior Analysis, 4, 257-264. 
Mayer, R. E. (2011). Multimedia learning and games. In S. Tobias \& J. D. Fletcher (Eds.), Computer games and instruction (pp. 281-305). Charlotte, NC: Information Age.

Means, B., Toyama, Y., Murphy, R., \& Baki, M. (2013). The effectiveness of online and blended learning: A meta-analysis of the empirical literature. Teachers College Record, 115(3), 1-47.

*Neumann, D. L., \& Hood, M. (2009). The effects of using a wiki on student engagement and learning of report writing skills in a university statistics course. Australasian Journal of Educational Technology, 25(3), 382-398.

*Newhouse, R., Buckley, K. M., Grant, M., \& Idzik, S. (2013). Reconceptualization of a doctoral EBP course from in-class to blended format: Lessons learned from a successful transition. Journal of Professional Nursing, 29(4), 225-232.

Pashler, H., Bain, P. M., Bottge, B. A., Graesser, A., Koedinger, K., McDaniel, M., et al. (2007). Organizing instruction and study to improve student learning (NCER 2007-2004). Washington, DC: National Center for Education Research, Institute of Education Sciences, U. S. Department of Education. $<$ http://ncer.ed.gov>.

*Pereira, J. A., Pleguezuelos, E., Merí, A., Molina-Ros, A., Molina-Tomás, M. C., \& Masdeu, C. (2007). Effectiveness of using blended learning strategies for teaching and learning human anatomy. Medical Education, 41(2), 189-195.

*Perkins, G. D., Kimani, P. K., Bullock, I., Clutton-Brock, T., Davies, R. P., Gale, M., et al. (2012). Improving the efficiency of advanced life support training: A randomized, controlled trial. Annals of Internal Medicine, 157(1), 19-28.

Picciano, A. G. (2009). Blending with purpose: The multimodal model. Journal of the Research Center for Educational Technology, 5(1), 4-14.

Picciano, A. G., Seaman, J., Shea, P., \& Swan, K. (2012). Examining the extent and nature of online learning in American K-12 education: The research initiatives of the Alfred P. Sloan Foundation. Internet and Higher Education, 15, 127-135.

*Riffell, S., \& Merrill, J. (2005). Do hybrid lecture formats influence laboratory performance in large, pre-professional biology courses? Journal of Natural Resources and Life Sciences Education, 34, 96-100.

Riffell, S., \& Sibley, D. (2005). Using web-based instruction to improve large undergraduate biology courses: An evaluation of a hybrid course format. Computers and Education, 44(3), 217-235.

Roediger, H. L., \& Karpicke, J. D. (2006). The power of testing memory: Basic research and implications for educational practice. Perspectives on Psychological Science, 1, 181-210.

Rudestam, K. E., \& Schoenholtz-Read, J. (2010). The flourishing of adult online education: An overview. In K. E. Rudestam \& J. Schoenholtz-Read (Eds.), Handbook of online learning (pp. 1-28). Thousand Oaks, CA: Sage.

*Sadaghiani, H. R. (2011). Using multimedia learning modules in a hybrid-online course in electricity and magnetism. Physical Review Special Topics Physics Education Research, 7(1), 010102.

*Salyers, V. L. (2005). Web-enhanced and face-to-face classroom instructional methods: Effects on course outcomes and student satisfaction. International Journal of Nursing Education Scholarship (IJNES), 2(1), Article 29.

*Salyers, V. L. (2007). Teaching psychomotor skills to beginning nursing students using a web-enhanced approach: A quasi-experimental study. International Journal of Nursing Education Scholarship (IJNES), 4(1), Article11.

Schmid, R. F., Bernard, R. M., Borokhovski, E., Tamim, R. M., Abrami, P. C., Surkes, M. A., et al. (2014). The effects of technology use in postsecondary education: A meta-analysis of classroom applications. Computers \& Education, 72, 271-291.

*Senn, G. J. (2008). Comparison of face-to-face and hybrid delivery of a course that requires technology skills development. Journal of Information Technology Education, 7, 267-283.

Sitzmann, T., Kraiger, K., Stewart, D., \& Wisher, R. (2006). The comparative effectiveness of web-based and classroom instruction: A meta-analysis. Personnel Psychology, 59, 623-664.

Smith, S. M., \& Rothkopf, E. Z. (1984). Contextual enrichment and distribution of practice in the classroom. Cognition and Instruction, 1, 341-358.

*Sung, Y. H., Kwon, I. G., \& Ryu, E. (2008). Blended learning on medication administration for new nurses: Integration of e-learning and face-to-face instruction in the classroom. Nurse Education Today, 28(8), 943-952.

Tamim, R. M. (2012). Blended learning for female empowerment: A United Arab Emirates case study. In R. Clothey, S. Austin-Li, \& J. C. Weidman (Eds.), Post-secondary education and technology: A global perspective on opportunities and obstacles to development (pp. 223-242). New York: Palgrave Macmillan.

Tamim, R. M., Bernard, R. M., Borokhovski, E., Abrami, P. C., \& Schmid, R. F. (2011). What forty years of research says about the impact of technology on learning: A second-order meta-analysis and validation study. Review of Educational Research, 81, 4-28.

*Taradi, S. K., Taradi, M., Radić, K., \& Pokrajac, N. (2005). Blending problem-based learning with web technology positively impacts student learning outcomes in acid-base physiology. Advances Physiology Education, 29(1), 35-39.

Van Merriënboer, J. J. G., Kirschner, P. A., \& Kester, L. (2003). Taking the load off a learner's mind: Instructional design for complex learning. Educational Psychologist, 38, 5-13.

*Vernadakis, N., Antoniou, P., Giannousi, M., Zetou, E., \& Kioumourtzoglou, E. (2011). Comparing hybrid learning with traditional approaches on learning the Microsoft Office Power Point 2003 program in tertiary education. Computers \& Education, 56(1), 188-199.

*Vernadakis, N., Giannousi, M., Tsitskari, E., Antoniou, P., \& Kioumourtzoglou, E. (2012). A comparison of student satisfaction between traditional and blended technology course offerings in physical education. Turkish Online Journal of Distance Education, 13(1), 137-147.

Wilson, D. B. (n.d.). Practical meta-analysis effect size calculator. <http://www.campbellcollaboration.org/escalc/html/EffectSizeCalculator-Home.php>.

*Woltering, V., Herrler, A., Spitzer, K., \& Spreckelsen, C. (2009). Blended learning positively affects students' satisfaction and the role of the tutor in the problem-based learning process: Results of a mixed-method evaluation. Advances in Health Sciences Education, 14(5), $725-738$.

*Yang, Y.-F. (2012). Blended learning for college students with English reading difficulties. Computer Assisted Language Learning, 25(5), 393-410.

*Yapici, İ. Ü., \& Akbayin, H. (2012). The effect of blended learning model on high school students' biology achievement and on their attitudes towards the internet. TOJET: The Turkish Online Journal of Educational Technology, 11(2), 228-237.

*York, R. O. (2008). Comparing three modes of instruction in a graduate social work program. Journal of Social Work Education, 44(2), 157-172. 